\title{
Recent Advances in Immunoliposome-Based Cancer Therapy
}

\author{
Seyedeh Hoda Alavizadeh ${ }^{1}$. Fatemeh Soltani ${ }^{2,3} \cdot$ Mohammad Ramezani $^{4}$
}

Published online: 15 March 2016

(C) Springer International Publishing AG 2016

\begin{abstract}
Advances in protein engineering have revolutionized nanomedicine by introducing novel nanocarriers for delivery of cancer therapeutics. Designing assemblies that simultaneously incorporate therapeutics and target the site of disease has been the focus of recent studies. Such devices have been developed to behave dynamically in response to certain cues to trigger drug release. Immunoliposomes have been regarded as an attractive drug targeting vehicle for cancer treatment. In the present review, we focus on recent advances in the design of immunoliposomes incorporating a variety of chemotherapeutics that simultaneously exhibit specific target-cell interactions and stimuli-sensitivity. We provided an overview of different stimuli-responsive immunoliposomes that are capable of controlling release of drug in response to either exogenous (temperature, light, and magnetic
\end{abstract}

This article is part of the Topical Collection on Drug Delivery

Mohammad Ramezani

ramezanim@mums.ac.ir

Seyedeh Hoda Alavizadeh

Alavizadehh891@mums.ac.ir

Fatemeh Soltani

SoltaniF@mums.ac.ir

1 Nanotechnology Research Center, School of Pharmacy, Mashhad University of Medical Sciences, Mashhad, Iran

2 Biotechnology Research Center, School of Pharmacy, Mashhad University of Medical Sciences, Mashhad, Iran

3 Department of Pharmaceutical Biotechnology, School of Pharmacy, Mashhad University of Medical Sciences, Mashhad, Iran

4 Pharmaceutical Research Center, School of Pharmacy, Mashhad University of Medical Sciences, Mashhad, Iran field) or endogenous (changes in $\mathrm{pH}$ and enzyme concentration) stimuli. We have discussed examples of stimulisensitive immunoliposomes with respect to each stimuli and their therapeutic potential for cancer treatment.

Keywords Immunoliposomes · Stimuli-responsive carriers · Antibody $\cdot$ Temperature $\cdot$ Enzymes

\section{Introduction}

Cancer is still one of the major causes of death worldwide, with more than 10 million new cases every year [1]. From a drug delivery perspective, general distribution of cancer therapeutic within the whole body and the subsequent toxicity to normal tissues limit drug bioavailability at the tumor site [2, 3]. It would be therefore desirable to develop site-specific pharmaceutical nanocarriers that can either passively or actively target cancerous cells [4-8]. Among different drugs and gene delivery approaches, liposomes offer several advantages such as biocompatibility, low toxicity, and the capacity to alter the pharmacokinetic profile of therapeutic agents [9]. Specifically, the incorporation of polyethylene glycol (PEG) coating on the surface of liposomes greatly enhances blood circulation half-life and promotes preferential localization at desired target tissue through the EPR $[10,11]$. This phenomenon, also termed as passive targeting, exploits the general features of tumor vasculature, including leaky blood vessels and poor lymphatic drainage, characteristics of rapid and defective angiogenesis which provide oxygen and nutrients for fast proliferating tumor cells (Fig. 1) [12]. Thus, carriers that are more likely to be cleared by reticuloendothelial system (RES) exploit this phenomenon to accumulate in tumor via multiple passages through the tumor sites [13••]. Though passive targeting approach forms the rational basis for the design 


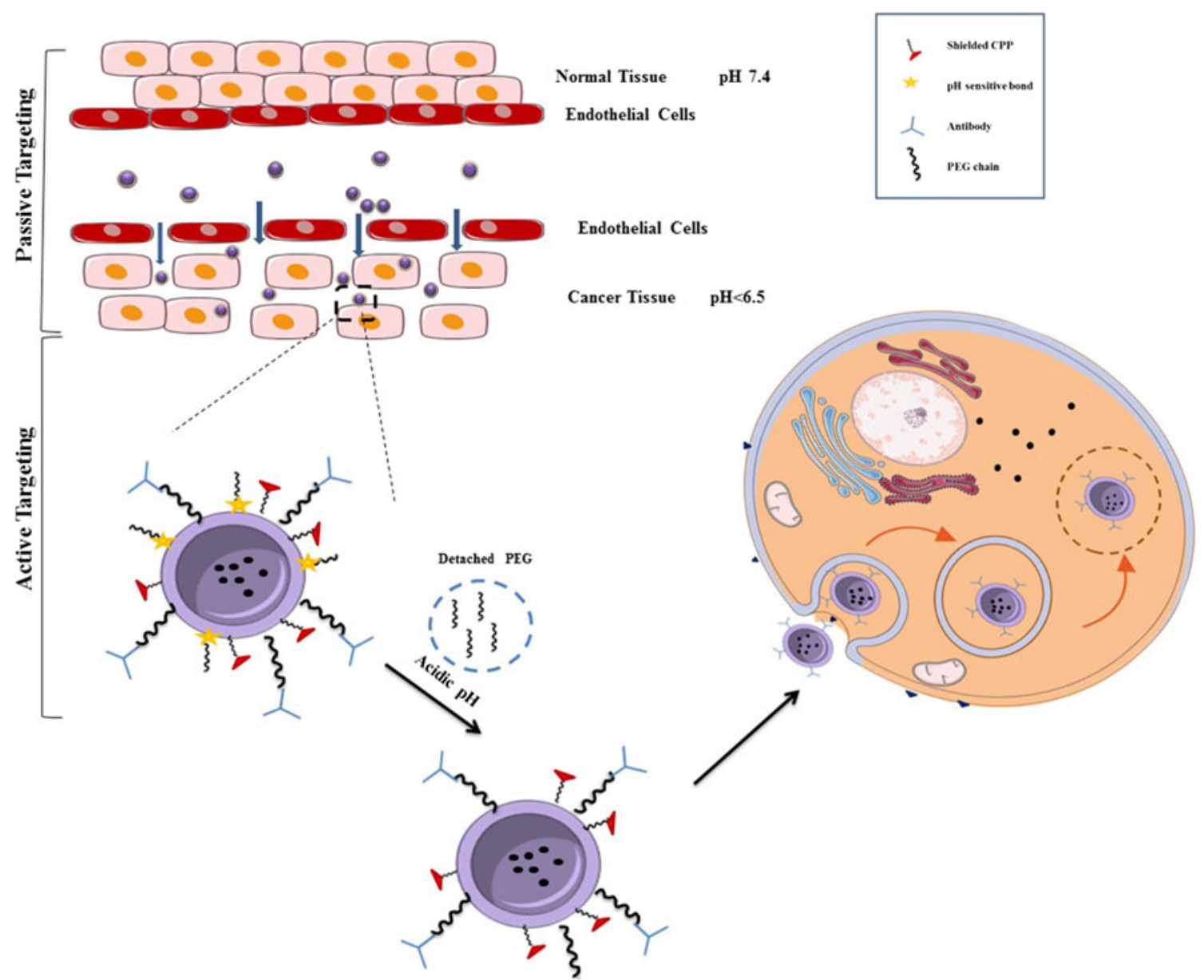

Fig. 1 Targeted drug delivery from $\mathrm{pH}$-sensitive immunoliposomes. For the intracellular drug delivery to the targeted site, the liposomes should possess (1) PEG coating for prolonged circulation, (2) targeting motifs such as monoclonal Abs for cell-specific interaction, and (3) stimuli- sensitive capabilities to respond to the pathological site characteristic to either release the cargo in the cytoplasm by escaping endosome or expose the hidden cell penetrating peptide moieties (CPP) by surface-attached $\mathrm{pH}$-sensitive coatings of drug carriers and modern therapies, it faces challenges related to variable vascular permeability, high tumor interstitial fluid pressure, inhomogeneous targeting of tumor cells within a tumor, and the likely occurrence of multiple drug resistance (MDR) [14]. Thus, improved specificity can be imparted by designing more sophisticated systems to selectively deliver drugs to the targeted tissue.

Liposomes can be surface functionalized with targeting ligands through a variety of conjugation chemistries available in review articles [15-17]. The grafting of targeting ligands is generally implemented to facilitate target cell recognition and cellular uptake of nanocarriers rather than improving overall tumor accumulation [18]. This suggested that after extravasation of targeted liposomes into the tumor interstitial space, cellular internalization would be enhanced through ligandreceptor interactions (Fig. 1) [19]. The choice of target receptor or antigen on cancer cell as well as the type of targeting ligand is among the most important parameters of efficient ligand-mediated liposomal drug delivery [20]. A number of targeting ligands have been investigated for the development of targeted liposomes including antibodies, nucleic acids, and small molecules (peptides, carbohydrates, vitamins, etc.); see review in [21••]. Among several homing devices, antibody coupled liposomes, also termed as immunoliposomes, have attracted considerable attention for the targeted therapies [22, 23].

\section{Immunoliposomes}

Immunoglobulins of IgG class and their fragments (Fragment antigen binding (Fab) or single-chain variable fragments $(\mathrm{scFV}))$ are among the most extensively studied ligands for targeted therapy and diagnosis of tumors by virtue of drugloaded liposomes. Following their first description in the 1980s [24], several promising studies on tumor targeting related to immunoliposomes have been conducted; see Ref [19] for review. Several methods using various advanced chemistries and techniques have also been reviewed for antibody coupling to the surface of long-circulating PEGylated 
liposomes $[17,25]$. Further, since PEG molecules can sterically interfere with the targeting ability of an antibody, numerous methods have been developed for antibody conjugation to the surface of PEG to exclude steric hindrance of ligand binding to the target $[26,27]$.

Interestingly, it was shown that the accumulation of antibody-modified liposomes was in some cases similar to that of nontargeted liposomes and based on EPR phenomenon [28]; thus, the higher anti-cancer activity of immunoliposomes might be associated with internalization of modified liposomes and efficient drug delivery inside cancer cells [29, 30]. The therapeutic effect also depends on antibody density on the surface of liposomes, since over-modifications of the surface have shown to compromise the longevity of liposomes in vivo [31]. Other essential parameters that determine the degree of immunoliposome targeting are the type of encapsulated drugs, the rate of drug release, and specific overexpression of antigens on tumor cells to ensure the optimized binding of liposomes to the target cancer cells [32].

\section{Therapeutic Availability of Immunoliposomes}

The fate of immunoliposomes following binding to the target influences the therapeutic outcome. After binding to tumor cell, the delivery of encapsulated compound can take place via four different mechanisms: (1) adsorption onto the cell surface, (2) fusion with the cell membrane, (3) exchange of lipid components with the cell membrane, and (4) endocytic pathways [19]. In the case of receptor-mediated endocytosis, drug-containing nanocarriers have to be able to penetrate inside cells, bypassing lysosomal degradation for efficient targeting of the intracellular compartment [33, 34]. Likewise, if the carrier is taken up by the cell via receptormediated endocytosis, the PEG coat on the surface may prohibit endosomal escape and the subsequent delivery to cytoplasm. Further, cell surface binding via the high-affinity interactions of immunoliposomes with receptors limits the distribution and deeper penetration of carrier within tumor through binding-site barrier mechanism [35]. Extracellular release on the other hand seems preferable due to the bystander effect which allows drugs to reach the cells that do not express the targeted antigens or that are not readily accessible to immunoliposomes [20]. Generally, the ability of antibodytargeted liposomes to increase the bioavailable drug concentrations depends on the rate of release of the entrapped drug from liposomes at the target site. Such a delivery system should simultaneously show longevity in blood stream to allow for target accumulation and possessing the ability to switch on and off certain functions when necessary. Recent reviews on switchable nano-systems for medical application have mainly focused on stimuli-responsive nanocarriers for drug delivery $[36,37,38 \bullet, 39 \bullet \bullet]$; a further aim of the present review is to briefly include an overview of the literature regarding stimuli-responsive targeted immunoliposomes which offers an additional platform for the successful drug and gene delivery to the tumors (Fig. 2).

\section{Smart Stimuli-Responsive Immunoliposomes}

In order to efficiently deliver the encapsulated compounds to the target cells, the stability of drugs in circulation must be maintained. Immunoliposomes have to exert actions after binding to their target receptors on the cell surface; however, this is not a guarantee for the intracellular delivery of the liposome contents. Generally, there are two main pathways for drug entry into targeted cells: first, selective uptake of liposomes by endocytosis or fusion with the cell membrane, leading to the intracellular release of drug and secondly, release of the entrapped contents in close proximity to target cells. Methods used to fabricate immunoliposomes for triggering the release of encapsulated drug provide a novel strategy in the assembly of smart multifunctional immunoliposomes, see $[40,41 \bullet \bullet$ for reviews. The ideal smart immunoliposome carriers should specifically accumulate in the target tissue and possess the capability to "switch on" certain functions upon the action of biological stimuli. This stimuli can be either intrinsic to the diseased area such as a change in the enzyme levels [42], $\mathrm{pH}$ [43] and temperature (noted for inflamed and neoplastic area), or external stimuli like magnetic fields [44], ultrasound [45], light, and heat (see Table 1). These novel approaches that exploit the altered tumor microenvironment may avoid the complications associated with receptor-specific targeting and give new insights for achieving better therapeutic outcome.

\section{Intrinsic Stimuli}

The upcoming sections discuss immuno-conjugated liposomes with the ability to tune the release of therapeutic payload upon exposure to intrinsic stimuli such as altered $\mathrm{pH}$ and differentially expressed enzymes.

\section{pH-Responsive Immunoliposomes}

Improving Endosomal Escape to Enhance Cytoplasmic Delivery of Drugs and Genes Certain ligands improve intracellular levels of the entrapped cargo by induction of receptormediated endocytosis, thus exposing the endocytosed material to acidic lysosomal compartment and the subsequent enzymatic degradation which limits its therapeutic potential. In particular, this is critical in the case of drugs susceptible to degradation including nucleic acid-related materials such as pDNA, siRNA, and shRNA, and also peptidic drug [18]. For these molecules, delivery vectors capable of releasing the 
Fig. 2 Schematic representation of stimuli-sensitive targeted immunoliposomes

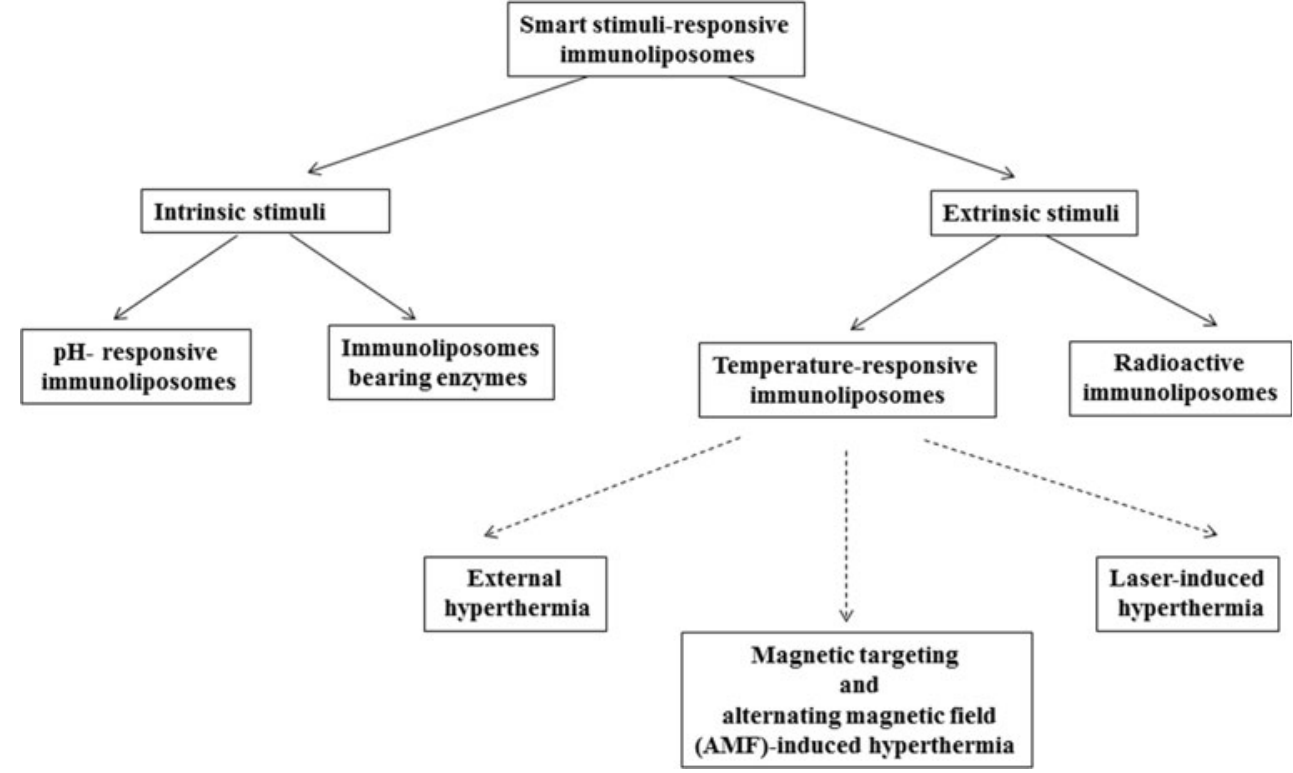

entrapped content into the cytoplasm of the target cells are advantageous; see review in [77]. There are generally two approaches through which cytosolic delivery can be achieved. The first mechanism involves fusion of immunoliposome with plasma membrane after their binding to the target cells. The endosomal escape of bioactive component into cytosol may also be enhanced by incorporating $\mathrm{pH}$-dependent fusogenic properties into the liposomal vehicle. In this case, $\mathrm{pH}-$ dependent fusion of ligand-targeted liposomes with the endosomal membrane following internalization via receptormediated endocytosis inhibits intralysosomal degradation [78]. The extracellular $\mathrm{pH}$ of tumors and other pathological sites is lower than that of blood and normal tissues $(\sim 6.5$ versus 7.4), due to the difference in their metabolic environment [79]. This feature has long been exploited by $\mathrm{pH}-$ responsive systems bearing $\mathrm{pH}$-cleavable bonds; while stable in blood and normal tissues, they disintegrate and release the drug load in areas with lowered $\mathrm{pH}[80,81]$. Different classes of $\mathrm{pH}$-sensitive liposomes have been proposed by tailoring liposomes with various $\mathrm{pH}$-labile components including phosphatidylethanolamine (PE) variants [82, 83], pH-sensitive lipids [84, 85], synthetic fusogenic peptides [20, 86, 87], polymers [88, 89], and polyethylene glycol derivatives [90]. So far, multiple attempts have been made to deliver drugs and genes into cytoplasm of tumor cells by virtue of $\mathrm{pH}$ sensitive liposomes, see reviews in [91, 92]. For example, the synthesis of a hydrazine-functionalized PEG-PE-BASED amphiphilic polymer has been reported which could conjugate a variety of ligands via a reversible $\mathrm{pH}$-labile bond, allowing for the targeting of liposomes to the desired site [46]. The majority of the initial works on $\mathrm{pH}$-sensitive systems focused on the combination of DOPE with amphiphilic stabilizers in liposomes with a strong tendency toward acquiring the inverted hexagonal phase upon acidic $\mathrm{pH}$ in the endosome [93]. Recent studies have mainly focused on combination of pH-sensitivity, longevity, and targeting ability of liposomes; see [94*•] for reviews. Folate-targeted liposomes composed of cationic and anionic lipid combinations exhibited superior serum stability compared to DOPE-based $\mathrm{pH}$-sensitive liposomes. Besides pH sensitivity, folate-mediated endocytosis provides liposomes with an ideal mechanism for cellspecific delivery of araC molecules [47]. The combination of NIPAM copolymer or vesicles containing DOPE and CHEMS with PEGylated lipid provided liposomes with $\mathrm{pH}-$ responsive property, as well as long circulation half-lives. Coupling these $\mathrm{pH}$-sensitive liposomes with anti CD-33 and EGFR mAbs has shown benefits in terms of tumor accumulation and endosomal escape for efficient cytoplasmic delivery $[48,49]$. Additionally, using lipid pairs with nonmatching acyl chain length in anti-HER2 lipid vesicles loaded with doxorubicin induced $\mathrm{pH}$-dependent permeability of the targeted bilayer due to defective packing of the lipids at the interphases of lipid domains [50].

Targeted $\mathrm{pH}$-sensitive liposomes have also been designed to induce the cytoplasmic release of oligonucleotides [95]. Guo et al. have recently prepared C-X-C chemokine receptor type 4 (CXCR4)-targeted $\mathrm{pH}$-sensitive immunoliposomes encapsulating Lcn2 siRNA, to target metastatic breast cancer [51]. They have shown that the simultaneous targeting of CXCR4 and silencing Len 2 via lowered $\mathrm{pH}$ was more effective in impeding breast cancer cell migration. Turner et al. have also developed PEGylated anionic liposomes as carrier of plasmid DNA to transfect CD3 T lymphocytes. The polyplex has shown significant gene transfer activity dependent on the charge ratio of the components [96]. 
Table 1 Illustrative examples of stimuli-sensitive liposomes for drug and gene delivery

\begin{tabular}{|c|c|c|c|c|c|}
\hline Platform & Stimuli & Payload & Target & Status & Ref. \\
\hline Liposome & $\mathrm{pH}$ & $\begin{array}{l}\text { Carboxyfluorescein } \\
\text { Con-A, avidin }\end{array}$ & Anti-2C5, 2G4 mAbs & In vitro & Biswas [46] \\
\hline Liposome & $\mathrm{pH}$ & $\begin{array}{l}\text { Cytosine-b-D-arabinofuranoside } \\
\text { luciferase reporter gene }\end{array}$ & Folate & In vitro & Shi [47] \\
\hline Liposome & $\mathrm{pH}$ & Cytosine arabinoside & Anti-CD33 mAb & In vitro & Simard [48] \\
\hline Liposome & $\mathrm{pH}$ & Gemcitabine & Anti-EGFR mAb & In vitro, in vivo & Kim [49] \\
\hline Liposome & $\mathrm{pH}$ & Doxorubicin & Anti-HER2 mAb & In vitro & Karve [50] \\
\hline Liposome & $\mathrm{pH}$ & Lipocalin-2 (Lcn2) siRNA & Anti-CXCR4 mAb & In vitro & Guo [51] \\
\hline Lipopolyplex & $\mathrm{pH}$ & Plasmid DNA & Anti-CD3 mAb & In vitro & Turner [96] \\
\hline Liposome & $\mathrm{pH}$ & GFP & TAT & In vitro, in vivo & Kale [103] \\
\hline Liposome & $\mathrm{pH}$ & Doxorubicin & Anti-2C5 mAb, TAT & In vitro & Koren [52•] \\
\hline Liposome & $\mathrm{pH}$ & Doxorubicin & Anti-2C5 mAb, TAT & In vitro, in vivo & Apte [53] \\
\hline $\begin{array}{l}\text { Liposome } \\
\text { Micelle }\end{array}$ & $\mathrm{pH}$ & Doxorubicin & Anti-2G4 mAb, TAT, biotin & In vitro & Sawant [104] \\
\hline Liposome & $\mathrm{pH}$ & Doxorubicin & Anti-CD19 mAb & In vitro, in vivo & Ishida [54] \\
\hline Liposome & Enzyme & Fluorescent-labeled & Anti-2C5 mAb, TAT & In vitro, in vivo & Zhu [55] \\
\hline Liposome & $\begin{array}{l}\text { Enzyme } \\
\mathrm{pH}\end{array}$ & shVEGF and DOX & Cell penetrating peptide & In vitro, in vivo & Huang [56] \\
\hline Liposome & Enzyme & Epirubicin-glucuronide & Anti-OV-TL3 F $\left(\mathrm{ab}^{\prime}\right)$ of $\mathrm{mAb}$ & In vitro & Vingerhoeds [57] \\
\hline Liposome & Enzyme & Daunorubicin-glucuronide & Anti-OV-TL3 F $\left(\mathrm{ab}^{\prime}\right)$ of $\mathrm{mAb}$ & In vitro & Vingerhoeds [58] \\
\hline Liposome & Enzyme & Epirubicin-glucuronide & $\begin{array}{l}\text { Anti-OV-TL3 F }\left(a b^{\prime}\right) \text { of } m A b \\
\text { Anti-323.A3 F }\left(a b^{\prime}\right) \text { of } m A b\end{array}$ & In vitro & Storm [59] \\
\hline Liposome & Enzyme & Calcein & anti 323.A3 F (ab') of mAb & In vitro & Fonseca [60] \\
\hline Liposome & Temperature & Uridine & Anti-H2 $K^{\mathrm{k}} \mathrm{mAb}$ & In vitro & Sullivan [61] \\
\hline Liposome & Temperature & Doxorubicin & Anti-HER2/neu F $\left(a b^{\prime}\right)$ of mAb & In vitro & Gaber [62] \\
\hline Liposome & Temperature & Calcein & Anti-HER2/neu affibody & In vitro & Puri [115] \\
\hline Liposome & Temperature & Doxorubicin & Anti-HER2/neu affibody & In vitro & Smith [63] \\
\hline Liposome & Temperature & Doxorubicin & CREKA peptide & In vitro, in vivo & Wang [118] \\
\hline Liposome & Magnetic & $\mathrm{Fe}_{3} \mathrm{O}_{4}$ & Anti-HER2 and CD20 mAb & In vitro & Ito [64] \\
\hline Liposome & Magnetic & $\mathrm{Fe}_{3} \mathrm{O}_{4}$ & Anti-HER2 mAb & In vivo & Kikumori [65] \\
\hline Liposome & Magnetic & Doxorubicin and $\mathrm{Fe}_{3} \mathrm{O}_{4}$ & Folate & In vitro & Pradhan [66] \\
\hline $\begin{array}{l}\text { Polymeric } \\
\text { liposome }\end{array}$ & Magnetic & Epidoxorubicin and $\mathrm{Fe}_{3} \mathrm{O}_{4}$ & RGD peptide & In vitro & $\mathrm{Su}[67]$ \\
\hline Liposome & Laser & Magneto-plasmonic nanoshells & Anti-HER2 mAb & In vitro & Khosroshahi [68] \\
\hline Liposome & UV & Doxorubicin & Anti-CD20 mAb & In vitro & Li [69] \\
\hline Liposome & Radioactive & $(\mathrm{Et} 4 \mathrm{~N}) 2(10) \mathrm{B} 10 \mathrm{H} 10$ & Anti-MGb 2 mAb & In vitro & $\mathrm{Xu}[70]$ \\
\hline Liposome & Radioactive & Docetaxel & Anti-carcinoembryonic $\mathrm{Ab}$ & In vitro & Wang [71] \\
\hline Liposome & Radioactive & Cisplatin & Anti-EGFR mAb & In vitro, in vivo & Jung [72] \\
\hline Liposome & Radioactive & ${ }^{111}$ In-labelled & Anti-2C5 mAb & In vivo & Elbayoumi, [73] \\
\hline Liposome & Radioactive & Technetium-99m & Anti-GAH F $\left(a b^{\prime}\right)$ of $m A b$ & In vivo & Kitamura [74] \\
\hline Liposome & Radioactive & Technetium-99m & Anti-EGFR and VEGF $\mathrm{mAb}$ & In vivo & $\mathrm{Li}[75]$ \\
\hline Liposome & Radioactive & Combretastatin & Cyclo RGD & In vivo & Pattillo [76] \\
\hline
\end{tabular}

Despite all the advances in preclinical and clinical studies, there are still many challenges in cancer therapy particularly siRNA therapeutics. The main hurdle is the delivery mechanism of the naked siRNA. Other than susceptibility to enzymatic degradation and unfavorable distribution, the surface charge and size of siRNA limit its passage through cell membrane. Numerous nanoparticulate systems have been heavily researched to enhance siRNA stability, cellular entry, and its biodistribution [97]. Lipid-based system carriers including cationic, fusogenic, neutral, and anionic lipids are versatile siRNA delivery vehicles that provide multifunctional features such as targeting, membrane fusion, and triggered release. However, due to the complexity of the biological environment, siRNA delivery vehicles are associated with toxicityrelated nonspecific immune stimulation, inflammatory responses, and consequently poor in vivo performance [98]. 
So, in order to carry these molecules into clinical trials, many challenges including rapid degradation, poor cellular uptake, and untoward side effects need to be clearly addressed. Despite this, the new class of therapeutics has shown improved efficacy in animal models and are currently entering clinical trials for the treatment of solid tumors [99].

\section{Detachable PEG Coating to Improve Target Cell}

Interaction Though longevity of immune-targeted liposomes in plasma is achieved by modification of the surface with PEG polymers, evidence demonstrates that steric stabilization is not desirable for all steps of drug delivery and may hinder drug release and target cell interaction. So, attempts have been made to enhance efficacy of PEG-liposomes by the loss of PEG after localization at the target site, thus facilitating liposome-cell interaction for efficient cargo delivery to the cells $[100,101]$. Torchilins' lab developed TAT-modified $\mathrm{pH}$-sensitive liposomes which showed improved internalization in tumor cells when administrated intratumorally in mice $[102,103]$. They hypothesized that after accumulation via EPR, the PEGylated liposomes lose their PEG coating inside the acidified tumor due to the hydrolysis of hydrazone bond and penetrate inside the cells via the exposed TAT moieties. Multifunctional $\mathrm{pH}$-sensitive immunoDoxil ${ }^{\circledR}$ conjugated with anti-nucleosome mAb 2C5 on the surface and further showed enhanced cytotoxicity after exposure to a lower $\mathrm{pH}$ environment [52•]. This system has successfully enhanced therapeutic efficacy in mice tumor xenografts through overcoming MDR in drug-resistant cells [53]. After deposition in the targeted organ, the pH-labile hydrazone bond between PEG and PE is cleaved in the acidified milieu, stimulating cell penetration via exposed TAT moieties [104]. The $\mathrm{pH}$-sensitive liposomes with chemically cleavable surface-grafted PEG (mPEG-S-SDSPE) have also been reported to actively deliver doxorubicin to the CD19 epitope of B-lymphoma cells, where cleavage of disulfide linkage by lysosomal enzymes allowed the rapid release of doxorubicin and consequently enhanced cytotoxicity [54]. To sum up, upon target-cell interaction of immunoliposomes, $\mathrm{pH}$-sensitivity could enhance the release of the entrapped contents into the cytoplasm. However, first, we have to consider that the $\mathrm{pH}$ difference is not uniform throughout the tumor tissue and can also fluctuate depending on the cancer type [39••], and second, the applicability of this mechanism largely depends on the endocytosis of the liposomes by the target cells and those systems that are not actively endocytosed may require alternative strategies.

\section{Immunoliposome Bearing Enzymes}

The significant internal physiological changes, such as an altered pattern of extracellular protein expression, have been used to develop stimuli-responsive nanocarriers. Enzymes for examples are crucial for the biochemical processes, and their expression varies greatly by tissue types. Extracellular matrix (ECM) remodeling proteinases such as the matrix metalloproteinases (MMPs) are known as the chief mediators of changes in the tumor microenvironment associated with the progression of tumors. The overexpression of MMP-2 has been shown in several clinical and preclinical investigations. Numerous MMP-2 substrates which designed with cleavable peptides have shown to be degradable in the presence of MMP-2 [105, 106]. Zhue et al. reported the design of $\mathrm{mAb}$ 2C5-targeted liposomes bearing MMP-2 cleavable octapeptide as a labile bond between long-chain PEG and lipid. When tested for in vitro cellular uptake, results indicated that the highly expressed extracellular MMP-2 degrades octapeptide linker in the tumor cells. This resulted in the exposure of TAT moieties on the surface of nanocarriers allowing for the enhanced cellular internalization and a greater cellular uptake [55]. In a more recent study, Huang et al. developed nanoparticles to co-deliver plasmid expressing interfering RNA targeting VEGF, and doxorubicin to effectively shut down blood vessels and induce cell apoptosis within the tumor. They decorate smart nanoparticles with a cell-penetrating peptide that was dual-triggered by the lowered tumor extracellular pH and MMP-2 to achieve efficient tumor targetability [56].

Another strategy concerns using enzymes with the potential to locally convert relatively nontoxic prodrugs into active cytotoxic agents. In this approach, known as antibodydirected enzyme prodrug therapy (ADEPT), administration of enzyme-coupled antibody prior to prodrug could selectively activate prodrug at the tumor site; see [107] for review. In an alternative approach, enzymes can be conjugated to the surface of immunoliposomes targeted to specific cancer cells, referred to as immune enzymosomes. The obvious advantages of immune-enzymosomes over enzyme-antibody conjugates include (1) efficient conversion of prodrug to active agent due to the high density of enzymes at tumor cell surface and (2) strong affinity of immunoliposomes for target cells through their multivalent binding features [59]. Storm's group first coupled the enzyme $\beta$-glucuronidase (GUS) to the surface of immunoliposomes bearing Fab fragments of the $\mathrm{mAb}$ OV-TL3. They indicated that the target binding potential of Fab, directed against human ovarian carcinoma cells, was preserved after coupling to immune-enzymosomes. Only in the cases of pretreatment of the target cells with immuneenzymosomes, the cytotoxicity enhancement of epirubicinglucuronide (epi-glu) prodrug was observed [57], which was further improved by increasing the enzyme density on the surface of immune-enzymosomes [58, 59]. However, above certain levels, the impairment of target cell binding of immune-enzymosomes occurred which was due to the steric hindrance effect mediated by high enzyme density on the surface of immunoliposomes [60]. Overall, designing nanoparticles which respond to enzymes is a fairly new strategy; however, with the rapid progress in biomarkers development and 
enzyme-sensitive substrate, in the years to come, we can expect a higher degree of sophistication in the design of theses smart nanocarriers.

\section{Extrinsic Stimuli}

\section{Temperature-Responsive Immunoliposomes}

External Hyperthermia Despite the great advantage of tumor-specific drug delivery and high uptake of immunoliposomal chemotherapeutics, further improvement could be achieved by applying an external trigger to smartly control drug bioavailability from liposomes [41••]. Mild hyperthermia (HT) has been shown to play a key role in modifying tumor microenvironment by increasing blood flow velocity, oxygenation, and vascular permeability [108]. Pioneering work by Dewhirst's group reported on increased vascular hyperpermeability after HT which lasted for several hours, resulting in increased liposome extravasation [109, 110]. In addition, HT may be used to trigger content release from liposomes incorporating thermosensitive moieties, like lysolipids or olygoglycerol-PG which induces a gel-to-liquid phase transition at the desired temperature leading to release of the entrapped contents [111]. Generally, the triggered release from thermosensitive liposomes is based on the lipiddestabilizing mechanism, phase transition effect, and the time and temperature schedule of the external HT [112]. Ideally, targeted immunoliposomes would result in an increased intracellular localization provided that ligands initiate receptor internalization [113]. Thus, combining the targeting functionality of immunoliposomes and their internalizing features with heat-triggerable characteristics ensures efficient release of the liposome-entrapped drug at the target site. Although literature on targeted immunoliposomes is limited, several groups have investigated this novel approach for targeted thermoresponsive drug delivery, as reviewed in [114••]. In 1986, Huang et al. described the first heat-sensitive immunoliposome that enhanced cellular uptake of uridine. They demonstrated that the enhancement of drug uptake was due to the release of drugs in close proximity to the cell surface by virtue of bound immunoliposomes [61]. Gaber et al. created sterically stabilized thermosensitive liposomes conjugated to the Fab fragments of HER2/neu, for the delivery of doxorubicin to the tumor using postinsertion technique. Uptake of HER2-immunoliposomes by HER2overexpressing SK-BR-3 cells was shown to be eight times higher than those of nontargeted liposomes for thermoresponsive and nonthermoresponsive liposomes. Though the toxicity of targeted thermosensitive liposomes was quite similar to that of free drug, heating cells to $42{ }^{\circ} \mathrm{C}$ after liposome incubation did not enhance the cytotoxicity of targeted immunoliposomes. On the whole, it was shown that the fast release of the entrapped drug by virtue of an external trigger does not necessarily contribute to the efficiency of targeted liposomes [62]. Puris' group investigated affibody affinity ligands as an alternative to antibodies for targeting drug delivery. They conjugated HER2-specific affibody to the surface of thermosensitive liposomes and determined thermosensitivity by temperature-induced leakage of calcein from liposomes. The DPPC-based thermoresponsive liposomes showed an optimal leakage (90-100\%) at $41^{\circ} \mathrm{C}$ and appropriate retention of the entrapped calcein in the presence of serum [115]. The same research group modified HER2 affibody by introducing a glycine-serine spacer to achieve more access to HER2 expressed on the target cells. Results indicated that the accumulation of HER2+ liposomes was at least twofold to threefold greater than control liposomes. However, cytotoxicity studies demonstrated that brief exposure of liposome-cell complexes at $45^{\circ} \mathrm{C}$ before the onset of incubation improved cell killing for both targeted and control liposomes [63].

It has been suggested that HT in combination with chemotherapy is playing an important role in the treatment of MDR $[116,117]$. In a more recent study, a CREKA-modified lysothermosensitive liposome containing doxorubicin was designed to overcome multidrug resistance in tumor cells. It was hypothesized that the tumor homing peptide CREKA would target the clotted plasma proteins in tumor vessels and releases a burst of the encapsulated doxorubicin in the heated tumor site. The in vivo anti-tumor results indicated that the highest drug concentration and antitumor activity during HT treatment was observed with targeted doxorubicin-loaded thermosensitive liposome [118].

\section{Magnetic Targeting and Alternating Magnetic Field} (AMF)-Induced HT An alternative approach in applying local HT treatment is magnetic targeting and alternating magnetic field (AMF)-induced HT. Iron oxide nanoparticles, known as superparamagnetic iron oxide nanoparticles (SPIONs), have been extensively utilized for simultaneous imaging and stimuli-responsive drug delivery [119••]. Additionally, magnetic nanoparticles can generate HT following the application of an alternating magnetic field which could damage tumor cells (Fig. 3), while normal cells remain unaffected. Ito et al. reported that $\mathrm{Fe}_{3} \mathrm{O}_{4}$-loaded anti-HER2 immunoliposomes under $42.5^{\circ} \mathrm{C}$ heat generated by AMF induced strong cytotoxic effects on SK-BR-3 breast cancer cells in vitro [64]. Another targeted magnetoliposomes to HER2+ breast cancer cells were developed by Kikumori et al. They investigated the feasibility of this modality in tumor-bearing mouse models and demonstrated a substantial tumor regression in the AMF-HT-treated animals [65]. Pradhan et al. also combined biological (folate) and physical (magnetic) drug targeting to use these features in magnetic HT-triggered drug release. To this end, they developed folate-targeted doxorubicin magnetoliposomes and showed that under a permanent 


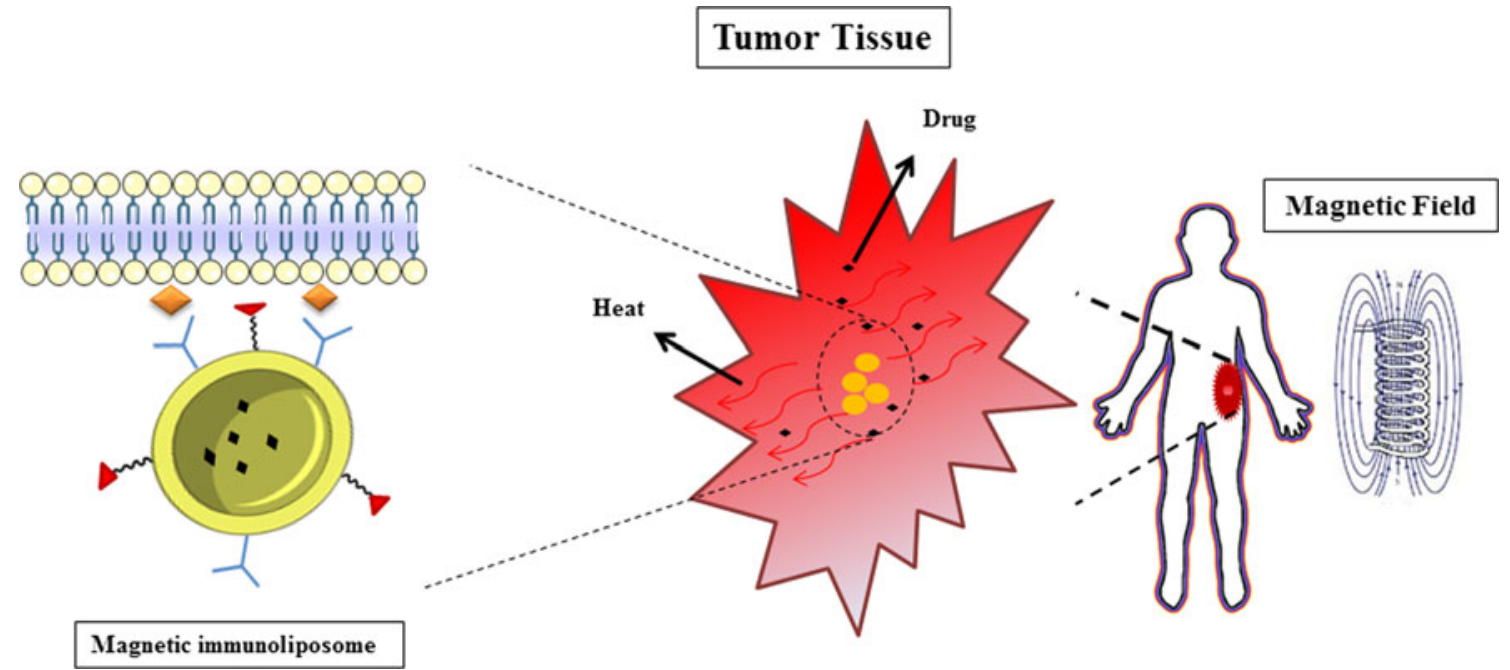

Fig. 3 Magnetic field-induced hyperthermia and drug release. The multifunctional immunoliposome can be targeted physically by means of magnetic field and also biologically by targeting moieties attached to their surface. Targeting immunoliposome would enhance receptor-

magnetic field, this formulation substantially increased doxorubicin cellular uptake compared to nonmagnetic liposomes in folate-receptor expressing tumor cell lines. Additionally, parallel increase in cell killing was also observed with these formulations [66]. More recently, PEG-RGD magnetic polymeric liposomes were developed as a multifunctional platform for targeted epidoxorubicin delivery to tumor cells. Results indicated that external magnetic field promotes accumulation of magnetic carrier on the surface of tumor cells where cellular uptake can be enhanced by RGD targeting to $\alpha v \beta 3$ on MCF7 tumor cells [67].

Laser-Induced Hyperthermia Light offers an interesting approach for use as an external stimulus due to noninvasiveness and suitable remote control over release of drugs from nanovehicles. Several photo-sensitive groups and a wide range of mechanisms are involved in light-triggered release of cargos from nanopreparations [39••]. Laser irradiations of gold nanostructures have been shown to induce local heating due to temperature rise, which can be directly transferred to the vicinity of nanostructure. Khosroshahi et al. have designed such magneto-plasmonic nanoshells (MPNS)-loaded liposomes for targeted laser-induced apoptosis in HER2overexpressing human breast carcinoma. Results demonstrated that the laser-induced release of carboxyfluorescein was due to the direct heating of liposomes and the subsequent effect on the permeability of lipid bilayers. Further, laser irradiation of Herceptin-mediated internalized MPNS-loaded liposomes resulted in cell apoptosis which was suggested to be due to photothermal bubble generation that thermally damaged cellular membrane [68]. In a more recent study, $\mathrm{Li}$ et al. used UV irradiation to improve the serum stability of CD20-targeting immunoliposome of doxorubicin [69]. They mediated uptake of nanoparticles into tumor cells followed by trigger release of the entrapped content through application of an external magnetic field

developed liposomes that can form chains of covalently linked lipids in the liposomal bilayers upon UV irradiation with slower and efficient drug release compared to nonirradiated liposomes.

\section{Radioactive Immunoliposomes}

Locoregional recurrence following surgery is a major problem in cancer treatment. To improve the overall patient survival and reduce the local recurrence rate after surgery, adjuvant chemotherapy and radiotherapy (RT) is given preoperatively or postoperatively. Since the discovery of liposomes 40 years ago, various methods of labeling liposomes with both diagnostic and therapeutic radionuclides have been developed [120]. Further development of monoclonal antibody makes it possible to enhance the selectivity of liposomes by a targeted delivery approach. In 1991, Xu et al. showed that SGC-7901 cells pretreated with boron-10 containing immunoliposomes survived only $27 \%$; this survival rate was significantly lower than nonirradiated or nonpretreated cells with irradiation [70]. Radiation also induces apoptosis in neoplastic cells, and the extent of apoptosis is closely related to radiosensitivity. Some chemotherapeutics possess the radiosensitizing properties for malignant tumors; however, in most instances, poor selectivity for targeted tumors lead to untoward side effects [121]. It has been reported that immunoliposomal docetaxel has strong radiosensitizing effect in LOVO colon carcinoma [71]. When combined with irradiation, antibody-conjugated liposomes substantially decreased the percentage of cells in $\mathrm{G} 2 / \mathrm{G} 1$ and $\mathrm{S}$ phases compared to liposomal docetaxel. In a more recent study, Jung et al. evaluated the radiosensitizing effect of EGFR-conjugated cisplatin-incorporated liposomes. They showed that treatment with a 
combination of immunoliposomes and radiation resulted in increased growth delay in xenograft tumor mouse model with reduced side effects [72].

Immunoliposomes have also been used as carriers of diagnostic agents for different imaging modalities including gamma scintigraphy, MRI, and computed tomography [122]. Torchilin laboratory developed ${ }^{111}$ In-labelled liposomes for in vivo biodistribution and tumor accumulation of $2 \mathrm{C} 5$ antibody-modified liposomes [73]. Gamma scintigraphic imaging of tumor-bearing mice exhibited faster and more efficient tumor accumulation of 2C5-modified liposomes compared to control in tumor models. In another study, immunoliposomes were labeled with Tc-99m, either specifically in fragment portion or entrapped within liposomes. Biodistribution data in xenografted model of human gastric cancer indicated that Tc-99m entrapped in liposomes demonstrated higher stability in vivo and was strongly taken up by the tumor compared to Tc-99m-labled liposomes [74]. Intracavitarily, injection of Tc-99m labeled panitumumaband bevacizumab-liposomes in the rat breast cancer xenograft model following tumor removal showed high intracavitary retention of liposomes [75]. The results generally indicate the increased potential of targeted liposomes in enhancing radiotherapy to decrease cancer recurrence with minimal systemic toxicity.

Another characteristic feature of radiation is upregulation of several adhesion molecules. Thus, carriers bearing on their surface, ligands specific to the radiation-induced upregulated adhesion molecules, would preferentially localize in the irradiated tumor regions. Based on this hypothesis, Kianis' group investigated targeting of antivascular drug, combretastatin, to the irradiated tumor via ligand-bearing liposomes. They showed that treatment with a single dose of irradiation plus immunoliposomes significantly delayed tumor growth compared to other treatment groups [76].

\section{Challenges in Developing Stimuli-Responsive Nanoparticles}

Many complexities confound the successful development of multifunctional and stimuli-sensitive drug delivery systems and their transition to clinic. The ideal intelligent nanosystem with the ability to incorporate a sufficient load of drug or nucleic acid-related materials should first deposit at the desired site of action and then deliver its load into targeted cells [123]. So, for both nonspecific and specific targeting, the principle of many drug delivery systems is based on the EPR phenomenon. Clinical outcome from nano-sized delivery systems, however, indicated that EPR-dependent drug delivery could be affected by numerous tumor biological factors. The experimental animal models may not be representative of clinical tumors in several key aspects. Besides, the difficulty of extravasation into the tumors with high interstitial fluid pressure and the reduced intratumoral mobility of drug carrier due to nonspecific interaction with ECM components in a chaotic tumor environment will certainly diminish the reliability of EPR effect. On the basis of tumor heterogeneity and the extremely complex tumor microenvironment, the EPR should only be considered when there is sufficient evidence of the tumor type susceptibility [124]. When developing targeted carriers, one has to keep in mind that though ligand targeting exhibited improved efficacy over passive targeting via enhanced cellular uptake, it raised new challenges including hindered diffusion and penetration through the tumor tissue, immune recognition, and longevity in circulation. Further, surface characteristics, shape, and size of nanoparticle play an important role in the ultimate pharmacokinetic and distribution of these targeted vehicles [18]. Though many ligandtargeted particulate nanomedicines have progressed into clinical trials, yet, none of them have been approved at this moment. In this case, increased understanding of the in vivo fate and interaction of the ligand-targeted vehicles with serum proteins and cells in human is important in advancing the clinical translation of such targeted particles [125]. Going one step further, combining stimuli-sensitive properties with targeted delivery could be beneficial in improving the therapeutic outcome. However, this approach is rather complex and this complexity adds new pitfalls in predicting the behavior of the switchable nano-system. These delivery systems have to carry various functional moieties on the surface and simultaneously possessing the capability to switch on certain functions under the action of local stimuli [39••]. Additional capability means additional synthetic and purification steps as well as elevated complexities and costs [126]. The feasibility of $\mathrm{pH}$-switchable system, for example, has been frequently reported, but the translation from bench to bedside is not straightforward. The applicability of $\mathrm{pH}$-sensitive nanoparticles profits from active targeting where ligand-induced receptor-mediated endocytosis is the principle mechanism [104]. Further, a different $\mathrm{pH}$ may be present in in vivo compared to the one tested under experimental in vitro condition. It should be considered that there may be upregulated proteins or high concentrations of enzymes in normal cells in the case of enzyme-responsive nano-vehicles. When the redox potential gradient is the local trigger, the low concentration of reducing agents in blood needs to be taken into account which may result in premature loss of the desired effect. In particular, endogenous stimuli are hard to control and they may vary from one patient to another. Exogenous trigger, on the other hand, offers more freedom in design; however, the biocompatibility of the external stimuli, level of tissue damage, the depth of penetration, and the time and the availability of external source location may restrict the

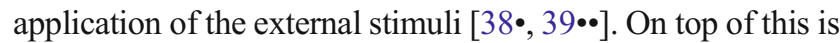
the difficulty in terms of manufacturing process and reproducibility of smart targeted delivery systems on a commercial 
scale which will come at the cost of additional financial hurdles [126]. To date, stimuli-sensitive nano-systems that have reached the clinical stage are based on exogenous stimuli, which may explain the variability associated with endogenous triggers. Thermodox, which is the thermoresponsive liposome of doxorubicin, has been used in clinical trials for the treatment of breast cancer (phase II) and hepatocellular carcinoma (phase III). However, it has recently been suspended due to a lack of sufficient improvement in the life span of patients [37].

Considering the above mentioned problems, clinical translation of the current knowledge on multifunctional delivery systems requires avoiding the complex multistep manufacturing processes. Additionally, scalability of such products should not be problematic and be based on accepted protocols [119••]. Indeed, the development of multifunctional and stimuli-responsive nanoparticles represents a new area in drug delivery systems, and if the requirements are met, the smart carriers could become an important part of the personalized therapy in upcoming years.

\section{Conclusion}

Over the past decade, a dramatic increase in the complexity of sophisticated nanocarriers has been observed. Particulate nanomedicines have evolved to overcome the major hurdles of drug targeting including the heterogeneity of the biological target and the limited bioavailability of the drugs. In this context, advances in polymer chemistry enable modification of nanocarriers for on-demand, stimuli-responsive release of the entrapped payload in the targeted tissue. As a result, nanopreparations incorporating multiple functions gained a lot of momentum; however, creating systems to simultaneously achieve targeted delivery through the attached ligands and respond to stimuli to trigger drug release is significantly more challenging than mono-therapies. Though proof of concept has been reported for several targeted stimuli-responsive nanoparticles, only a few have been assessed in in vivo preclinical models and none of them have yet reached clinical phase studies. On the whole, for these systems, complex, multifaceted architectural design, difficulties in scaling-up, insufficient biocompatibility, and the microenvironmental heterogeneity likely hamper the translation from bench to bedside and, however, do not make it impossible. The representative examples highlight just a few of the outstanding potential of nanomedicines for the development of combination therapies. In the next generation of delivery vehicles, we would expect a higher level of sophistications in the design of these systems.
Acknowledgments Funding was received from Mashhad University of Medical Sciences, Mashhad, Iran.

\section{Compliance with Ethical Standards}

Conflict of Interest The authors confirm that this article content has no conflict of interest.

Human and Animal Rights and Informed Consent This article does not contain any studies with human or animal subjects performed by any of the authors.

\section{References}

Papers of particular interest, published recently, have been highlighted as:

- Of importance

•• Of major importance

1. Peer D, Karp J, Hong S, Farokhzad O, Margalit R, Langer R. Nanocarriers as an emerging platform for cancer therapy. Nat Nanotechnol. 2007;2(12):751-60.

2. Ferrari M. Cancer nanotechnology: opportunities and challenges. Nat Rev Cancer. 2005;5(3):161-71.

3. Alonso M. Nanomedicines for overcoming biological barriers. Biomed Pharmacother. 2004;58(3):168-72.

4. Torchilin VP. Targeted pharmaceutical nanocarriers for cancer therapy and imaging. AAPS J. 2007;9(2):128-47.

5. Matsumura Y. DDS in cancer chemotherapy. Biotherapy. 2004;18(4):339-51.

6. Guillemard V, Saragovi HU. Novel approaches for targeted cancer therapy. Curr Cancer Drug Tar. 2004;4(4):313-26.

7. Fernandes E, Ferreira JA, Andreia P, Luís L, Barroso S, Sarmento $B$, et al. New trends in guided nanotherapies for digestive cancers: a systematic review. J Control Release. 2015;209:288-307.

8. Brayden DJ. Controlled release technologies for drug delivery. Drug Discov Today. 2003;8(21):976-8.

9. Torchilin VP. Recent advances with liposomes as pharmaceutical carriers. Nat Rev Drug Discov. 2005;4(2):145-60.

10. Maeda H, Wu J, Sawa T, Matsumura Y, Hori K. Tumor vascular permeability and the EPR effect in macromolecular therapeutics: a review. J Control Release. 2000;65(1-2):271-84.

11. Maeda H. Enhanced permeability and retention (EPR) efect: basis for drug targeting to tumor. Biomedical aspects of drug targeting. Springer; 2002. p. 211-28.

12. Maruyama K. Intracellular targeting delivery of liposomal drugs to solid tumors based on EPR effects. Adv Drug Deliver Rev. 2011;63(3):161-9.

13.• Allen T, Cullis P. Liposomal drug delivery systems: from concept to clinical applications. Adv Drug Deliver Rev. 2013;65(1):36-48. Provides a comperhensive overview on the evolutuion of liposome drug delivery systems.

14. Nichols J, Bae Y. EPR: evidence and fallacy. J Control Release. 2014;190:451-64.

15. Allen TM, Brandeis E, Hansen CB, Kao GY, Zalipsky S. A new strategy for attachment of antibodies to sterically stabilized liposomes resulting in efficient targeting to cancer cells. Biochim Biophys Acta. 1995;1237(2):99-108.

16. Torchilin V, Goldmacher V, Smirnov V. Comparative studies on covalent and noncovalent immobilization of protein 
molecules on the surface of liposomes. Biochem Bioph Res Co. 1978;85(3):983-90.

17. Hansen C, Kao G, Moase E, Zalipsky S, Allen T. Attachment of antibodies to sterically stabilized liposomes: evaluation, comparison and optimization of coupling procedures. Biochim Biophys Acta. 1995;1239(2):133-44.

18. Sawant RR, Torchilin VP. Challenges in development of targeted liposomal therapeutics. AAPS Journal. 2012;14(2):303-15.

19. Torchilin V. Antibody-modified liposomes for cancer chemotherapy. Expert Opin Drug Del. 2008;5(9):1003-25.

20. Mastrobattista E, Koning G, Storm G. Immunoliposomes for the targeted delivery of antitumor drugs. Adv Drug Deliver Rev. 1999;40(1-2):103-27.

21.• Noble GT, Stefanick JF, Ashley JD, Kiziltepe T, Bilgicer B. Ligand-targeted liposome design: challenges and fundamental considerations. Trends Biotechnol. 2014;32(1):32-45. Focuses on the recent challenges encountering ligand-targeted liposome application and the advanced strategies used to overcome them.

22. Kontermann RE. Immunoliposomes for cancer therapy. Curr Opin Mol Ther. 2006;8(1):39-45.

23. Vingerhoeds M, Storm G, Crommelin D. Immunoliposomes in vivo. Immuno Methods. 1994;4(3):259-72.

24. Bendas G. Immunoliposomes: a promising approach to targeting cancer therapy. BioDrugs. 2001;15(4):215-24.

25. Torchilin VP. Liposomes as targetable drug carriers. Crit Rev Ther Drug Carrier Syst. 1985;2(1):65-115.

26. Sawant R, Torchilin V. Design and synthesis of novel functional lipid-based bioconjugates for drug delivery and other applications. Methods Mol Biol. 2010;751:357-78.

27. Torchilin VP, Levchenko TS, Lukyanov AN, Khaw BA, Klibanov AL, Rammohan R, et al. p-Nitrophenylcarbonyl-PEG-PE-liposomes: fast and simple attachment of specific ligands, including monoclonal antibodies, to distal ends of PEG chains via $\mathrm{p}$ nitrophenylcarbonyl groups. Biochimica Et Biophysica Acta. 2001;1511(2):397-411.

28. Moreira J, Gaspar R, Allen T. Targeting Stealth liposomes in a murine model of human small cell lung cancer. Biochim Biophys Acta. 2001;1515(2):167-76.

29. Kirpotin DB, Drummond DC, Shao Y, Shalaby MR, Hong K, Nielsen UB, et al. Antibody targeting of long-circulating lipidic nanoparticles does not increase tumor localization but does increase internalization in animal models. Cancer Res. 2006;66(13):6732-40.

30. Park JW, Kirpotin DB, Hong K, Shalaby R, Shao Y, Nielsen UB, et al. Tumor targeting using anti-her2 immunoliposomes. J Control Release. 2001;74(1-3):95-113.

31. Sapra P, Tyagi P, Allen TM. Ligand-targeted liposomes for cancer treatment. Curr Drug Deliv. 2005;4:369-81.

32. Maclean AL, Symonds G, Ward R. Immunoliposomes as targeted delivery vehicles for cancer therapeutics (review). Int J Oncol. 1997;11(2):325-32.

33. Torchilin V. Fluorescence microscopy to follow the targeting of liposomes and micelles to cells and their intracellular fate. Adv Drug Deliv Rev. 2005;57(1):95-109.

34. Varga C, Wickham T, Lauffenburger D. Receptor-mediated targeting of gene delivery vectors: insights from molecular mechanisms for improved vehicle design. Biotechnol Bioeng. 2000;70(6):593-605.

35. Sapra P, Allen T. Ligand-targeted liposomal anticancer drugs. Prog Lipid Res. 2003;42(5):439-62

36. Preiss M, Bothun G. Stimuli-responsive liposome-nanoparticle assemblies. Expert Opin Drug Del. 2011;8(8):1025-40.

37. Mura S, Nicolas J, Couvreur P. Stimuli-responsive nanocarriers for drug delivery. Nat Mater. 2013;12(11):991-1003.
38. Lehner R, Wang X, Wolf M, Hunziker P. Designing switchable nanosystems for medical application. J Control Release. 2012;161(2):307-16. Indicates challenges facing switchable nanosystems for medical applications.

39.• Jhaveri A, Deshpande P, Torchilin V. Stimuli-sensitive nanopreparations for combination cancer therapy. J Control Release. 2014;190:352-70. Provides an overview of stimuliresponsive nanopreparations for cancer therapy with respect to different internal and external stimuli.

40. Ganta S, Devalapally H, Shahiwala A, Amiji M. A review of stimuli-responsive nanocarriers for drug and gene delivery. J Control Release. 2008;126(3):187-204.

41.• Koshkaryev A, Sawant R, Deshpande M, Torchilin V. Immunoconjugates and long circulating systems: origins, current state of the art and future directions. Adv Drug Deliv Rev. 2013;65(1):24-35. Focuses on the recent development of immuno-targeted drug delivery systems including longcirculating immunoliposomes and immunomicelles.

42. Basel M, Shrestha T, Troyer D, Bossmann S. Protease-sensitive, polymer-caged liposomes: a method for making highly targeted liposomes using triggered release. ACS Nano. 2011;5(3):216275 .

43. Wike-Hooley J, Haveman J, Reinhold H. The relevance of tumour $\mathrm{pH}$ to the treatment of malignant disease. Radiother Oncol. 1984;2(4):343-66.

44. Tagami T, Foltz WD, Ernsting MJ, Lee CM, Tannock IF, May JP, et al. MRI monitoring of intratumoral drug delivery and prediction of the therapeutic effect with a multifunctional thermosensitive liposome. Biomaterials. 2011;32(27):6570-8.

45. Schroeder A, Honen R, Turjeman K, Gabizon A, Kost J, Barenholz Y. Ultrasound triggered release of cisplatin from liposomes in murine tumors. J Control Release. 2009;137(1):63-8.

46. Biswas S, Dodwadkar N, Sawant R, Torchilin V. Development of the novel PEG-PE-based polymer for the reversible attachment of specific ligands to liposomes: synthesis and in vitro characterization. Bioconjug Chem. 2011;22(10):2005-13.

47. Shi G, Guo W, Stephenson S, Lee R. Efficient intracellular drug and gene delivery using folate receptor-targeted $\mathrm{pH}$-sensitive liposomes composed of cationic/anionic lipid combinations. J Control Release. 2002;80(1-3):309-19.

48. Simard P, Leroux JC. pH-sensitive immunoliposomes specific to the CD33 cell surface antigen of leukemic cells. Int J Pharm. 2009;381(2):86-96.

49. Kim IY, Kang YS, Lee DS, Park HJ, Choi EK, Oh YK, et al. Antitumor activity of EGFR targeted $\mathrm{pH}$-sensitive immunoliposomes encapsulating gemcitabine in A549 xenograft nude mice. J Control Release. 2009;140(1):55-60.

50. Karve S, Alaouie A, Zhou Y, Rotolo J, Sofou S. The use of pHtriggered leaky heterogeneities on rigid lipid bilayers to improve intracellular trafficking and therapeutic potential of targeted liposomal immunochemotherapy. Biomaterials. 2009;30(30):6055-64.

51. Guo P, You JO, Yang J, Jia D, Moses MA, Auguste DT. Inhibiting Metastatic Breast Cancer Cell Migration via the Synergy of Targeted, pH-triggered siRNA Delivery and Chemokine Axis Blockade. Mol Pharm. 2014;11(3):755-65.

52. Koren E, Apte A, Jani A, Torchilin VP. Multifunctional PEGylated 2C5-immunoliposomes containing $\mathrm{pH}$-sensitive bonds and TAT peptide for enhanced tumor cell internalization and cytotoxicity. J Control Release. 2012;160(2):264-73. Investigates the "shielding" effects of TAT by long PEG chains using different liposome models.

53. Apte A, Koren E, Koshkaryev A, Torchilin V. Doxorubicin in TAT peptide-modified multifunctional immunoliposomes demonstrates increased activity against both drug-sensitive and drug-resistant ovarian cancer models. Cancer Biol Ther. 2014;15(1):69-80. 
54. Ishida T, Kirchmeier M, Moase E, Zalipsky S, Allen T. Targeted delivery and triggered release of liposomal doxorubicin enhances cytotoxicity against human B lymphoma cells. Biochim Biophys Acta. 2001;1515(2):144-58.

55. Zhu L, Kate P, Torchilin V. Matrix metalloprotease 2-responsive multifunctional liposomal nanocarrier for enhanced tumor targeting. ACS Nano. 2012;6(4):3491-8.

56. Huang S, Shao K, Liu Y, Kuang Y, Li J, An S, et al. Tumortargeting and microenvironment-responsive smart nanoparticles for combination therapy of antiangiogenesis and apoptosis. ACS Nano. 2013;7(3):2860-71.

57. Vingerhoeds $M$, Haisma $H$, van Muijen $M$, van de Rijt R, Crommelin D, Storm G. A new application for liposomes in cancer therapy. Immunoliposomes bearing enzymes (immunoenzymosomes) for site-specific activation of prodrugs. Febs Lett. 1993;336(3):485-90.

58. Vingerhoeds MH, Haisma HJ, Belliot SO, Smit RHP, Crommelin DJA, Storm G. Immunoliposomes as enzyme-carriers (immunoenzymosomes) for antibody-directed enzyme prodrug therapy (ADEPT): optimization of prodrug activating capacity. Pharm Res. 1996;13(4):604-10.

59. Storm G, Vingerhoeds MH, Crommelin DJA, Haisma HJ. Immunoliposomes bearing enzymes (immuno-enzymosomes) for site-specific activation of anticancer prodrugs. Adv Drug Deliv Rev. 1997;24(2-3):225-31.

60. Fonseca MJ, Haisma HJ, Klaassen S, Vingerhoeds MH, Storm G. Design of immuno-enzymosomes with maximum enzyme targeting capability: effect of the enzyme density on the enzyme targeting capability and cell binding properties. Biochim Biophys Acta. 1999;1419(2):272-82.

61. Sullivan S, Huang L. Enhanced delivery to target cells by heatsensitive immunoliposomes. Proc Natl Acad Sci U S A. 1986;83(16):6117-21.

62. Gaber MH, Hong K. Targeted sterically stabilized immunoliposomes: effect of bilayer composition and temperature on the antitumor activity in vitro. Deutsche Zeitschrift für Onkologie. 2000;32(3):78-85.

63. Smith B, Lyakhov I, Loomis K, Needle D, Baxa U, Yavlovich A, et al. Hyperthermia-triggered intracellular delivery of anticancer agent to HER2 $(+)$ cells by HER2-specific affibody (ZHER2-GSCys)-conjugated thermosensitive liposomes (HER2 (+) affisomes). J Control Release. 2011;153(2):187-94.

64. Ito A, Kuga Y, Honda H, Kikkawa H, Horiuchi A, Watanabe Y, et al. Magnetite nanoparticle-loaded anti-HER2 immunoliposomes for combination of antibody therapy with hyperthermia. Cancer Lett. 2004;212(2):167-75.

65. Kikumori T, Kobayashi T, Sawaki M, Imai T. Anti-cancer effect of hyperthermia on breast cancer by magnetite nanoparticle-loaded anti-HER2 immunoliposomes. Breast Cancer Res Tr. 2009;113(3):435-41.

66. Pradhan P, Giri J, Rieken F, Koch C, Mykhaylyk O, Döblinger M, et al. Targeted temperature sensitive magnetic liposomes for thermo-chemotherapy. J Control Release. 2010;142(1):108-21.

67. Su W, Wang H, Wang S, Liao Z, Kang S, Peng Y, et al. PEG/RGD-modified magnetic polymeric liposomes for controlled drug release and tumor cell targeting. Int $\mathrm{J}$ Pharm. 2012;426(1-2):170-81.

68. Khosroshahi ME, Hassannejad Z, Firouzi M, Arshi AR. Nanoshell-mediated targeted photothermal therapy of HER2 human breast cancer cells using pulsed and continuous wave lasers: an in vitro study. Laser Med Sci. 2015;30(7):1913-22.

69. Li H, Guo K, Wu C, Shu L, Guo S, Hou J et al. Controlled and Targeted Drug Delivery by a UV-responsive Liposome for Overcoming Chemo-resistance in Non-Hodgkin Lymphoma. Chem Biol Drug Des. 2015:783-94.
70. $\mathrm{Xu} \mathrm{L}$. Boron neutron capture therapy of human gastric cancer by boron-containing immunoliposomes under thermal neutron irradiation. Zhonghua Yi Xue Za Zhi. 1991;71(10):568-71.

71. Wang QW, Lü HL, Song CC, Liu H, Xu CG. Radiosensitivity of human colon cancer cell enhanced by immunoliposomal docetaxel. World J Gastroentero. 2005;11(26):4003-7.

72. Jung J, Jeong S, Park S, Shin S, Ju E, Choi J, et al. A cisplatinincorporated liposome that targets the epidermal growth factor receptor enhances radiotherapeutic efficacy without nephrotoxicity. Int J Oncol. 2015;46(3):1268-74.

73. Elbayoumi T, Torchilin V. Enhanced accumulation of longcirculating liposomes modified with the nucleosome-specific monoclonal antibody $2 \mathrm{C} 5$ in various tumours in mice: gammaimaging studies. Eur J Nucl Med Mol I. 2006;33(10):1196-205.

74. Kitamura N, Shigematsu N, Nakahara T, Kanoh M, Hashimoto J, Kunieda E, et al. Biodistribution of immunoliposome labeled with Tc-99m in tumor xenografted mice. Ann Nucl Med. 2009;23(2): 149-53.

75. Li S, Goins B, Hrycushko BA, Phillips WT, Bao A. Feasibility of eradication of breast cancer cells remaining in postlumpectomy cavity and draining lymph nodes following intracavitary injection of radioactive immunoliposomes. Mol Pharm. 2012;9(9):2513-22.

76. Pattillo CB, Venegas B, Donelson FJ, Del Valle L, Knight LC, Chong PLG, et al. Radiation-guided targeting of combretastatin encapsulated immunoliposomes to mammary tumors. Pharm Res. 2009;26(5):1093-100.

77. Nimesh S, Gupta N, Chandra R. Strategies and advances in nanomedicine for targeted siRNA delivery. Nanomedicine. 2011;6(4):729-46.

78. Baum P, Müller D, Rüger R, Kontermann RE. Single-chain Fv immunoliposomes for the targeting of fibroblast activation protein-expressing tumor stromal cells. J Drug Target. 2007;15(6):399-406.

79. Vaupel P, Kallinowski F, Okunieff P. Blood flow, oxygen and nutrient supply, and metabolic microenvironment of human tumors: a review. Cancer Res. 1989;49(23):6449-65.

80. Collins D, Huang L. Cytotoxicity of diphtheria toxin A fragment to toxin-resistant murine cells delivered by $\mathrm{pH}$-sensitive immunoliposomes. Cancer Res. 1987;47(3):735-9.

81. Connor J, Huang L. Efficient cytoplasmic delivery of a fluorescent dye by pH-sensitive immunoliposomes. J Cell Biol. 1985;101(2): 582-9.

82. Litzinger D, Huang L. Phosphatidylethanolamine liposomes: drug delivery, gene transfer and immunodiagnostic applications. Biochim Biophys Acta. 1992;1113(2):201-27.

83. Torchilin VP, Zhou F, Huang L. pH-sensitive liposomes. J Liposome Res. 1993;3(2):201-55.

84. Kono K, Zenitani K, Takagishi T. Novel pH-sensitive liposomes: liposomes bearing a poly (ethylene glycol) derivative with carboxyl groups. Biochim Biophys Acta. 1994;1193(1):1-9.

85. Sudimack J, Guo W, Tjarks W, Lee R. A novel pH-sensitive liposome formulation containing oleyl alcohol. Biochim Biophys Acta. 2002;1564(1):31-7.

86. Provoda C, Stier E, Lee K. Tumor cell killing enabled by listeriolysin O-liposome-mediated delivery of the protein toxin gelonin. J Biol Chem. 2003;278(37):35102-8.

87. Subbarao NK, Parente RA, Szoka Jr FC, Nadasdi L, Pongracz K. pH-dependent bilayer destabilization by an amphipathic peptide. Biochemistry. 1987;26(11):2964-72.

88. Roux E, Francis M, Winnik F, Leroux J. Polymer based pHsensitive carriers as a means to improve the cytoplasmic delivery of drugs. Int J Pharm. 2002;242(1-2):25-36.

89. Roux E, Stomp R, Giasson S, Pézolet M, Moreau P, Leroux J. Steric stabilization of liposomes by $\mathrm{pH}$-responsive N- 
isopropylacrylamide copolymer. J Pharm Sci. 2002;91(8): 1795-802.

90. Mizoue T, Horibe T, Maruyama K, Takizawa T, Iwatsuru M, Kono $\mathrm{K}$, et al. Targetability and intracellular delivery of anti-BCG antibody-modified, $\mathrm{pH}$-sensitive fusogenic immunoliposomes to tumor cells. Int J Pharm. 2002;237(1-2):129-37.

91. Drummond D, Zignani M, Leroux J. Current status of $\mathrm{pH}-$ sensitive liposomes in drug delivery. Prog Lipid Res. 2000;39(5):409-60.

92. Simões S, Moreira J, Fonseca C, Düzgünes N, de Lima M. On the formulation of $\mathrm{pH}$-sensitive liposomes with long circulation times. Adv Drug Deliv Rev. 2004;56(7):947-65.

93. Düzgüneș N, Straubinger RM, Baldwin PA, Friend DS, Papahadjopoulos D. Proton-induced fusion of oleic acidphosphatidylethanolamine liposomes. Biochemistry. 1985;24(13):3091-8.

94.•• Paliwal SR, Paliwal R, Vyas SP. A review of mechanistic insight and application of $\mathrm{pH}$-sensitive liposomes in drug delivery. Drug Deliv. 2015;22(3):231-42. Highlights the mechanism and application of $\mathrm{pH}$-sensitive liposomes in chemotherapy and diagnostic.

95. Fattal E, Couvreur P, Dubernet C. "Smart" delivery of antisense oligonucleotides by anionic $\mathrm{pH}$-sensitive liposomes. Adv Drug Deliv Rev. 2004;56(7):931-46.

96. Turner C, Weir N, Catterall C, Baker TS, Jones MN. The transfection of Jurkat T-leukemic cells by use of $\mathrm{pH}$-sensitive immunoliposomes. J Liposome Res. 2002;12(1-2):45-50.

97. Shen H, Sun T, Ferrari M. Nanovector delivery of siRNA for cancer therapy. Cancer Gene Ther. 2012;19(6):367-73.

98. Foged C. siRNA delivery with lipid-based systems: promises and pitfalls. Curr Top Med Chem. 2012;12(2):97-107.

99. Ozcan G, Ozpolat B, Coleman R, Sood A, Lopez-Berestein G. Preclinical and clinical development of siRNA-based therapeutics. Adv Drug Deliv Rev. 2015;87:108-19.

100. Kaasgaard T, Mouritsen O, Jørgensen K. Screening effect of PEG on avidin binding to liposome surface receptors. Int J Pharm. 2001;214(1-2):63-5.

101. Romberg B, Hennink W, Storm G. Sheddable coatings for longcirculating nanoparticles. Pharm Res. 2008;25(1):55-71.

102. Kale AA, Torchilin VP. "Smart" drug carriers: PEGylated TATpmodified pH-sensitive liposomes. J Liposome Res. 2007;17(3-4): 197-203.

103. Kale AA, Torchilin VP. Environment-responsive multifunctional liposomes. Methods Mol Biol. 2010;605:213-42.

104. Sawant RM, Hurley JP, Salmaso S, Kale A, Tolcheva E, Levchenko TS, et al. "SMART" drug delivery systems: doubletargeted $\mathrm{pH}$-responsive pharmaceutical nanocarriers. Bioconjug Chem. 2006;17(4):943-9.

105. Mansour A, Drevs J, Esser N, Hamada F, Badary O, Unger C, et al. A new approach for the treatment of malignant melanoma: enhanced antitumor efficacy of an albumin-binding doxorubicin prodrug that is cleaved by matrix metalloproteinase 2 . Cancer Res. 2003;63(14):4062-6.

106. Terada T, Iwai M, Kawakami S, Yamashita F, Hashida M. Novel PEG-matrix metalloproteinase-2 cleavable peptide-lipid containing galactosylated liposomes for hepatocellular carcinomaselective targeting. J Control Release. 2006;111(3):333-42.

107. Senter P, Springer C. Selective activation of anticancer prodrugs by monoclonal antibody-enzyme conjugates. Adv Drug Deliv Rev. 2001;53(3):247-64.
108. Palazzi M, Maluta S, Dall'Oglio S, Romano M. The role of hyperthermia in the battle against cancer. Tumori. 2010;96(6):90210.

109. Andresen TL, Jensen SS, Jørgensen K. Advanced strategies in liposomal cancer therapy: problems and prospects of active and tumor specific drug release. Prog Lipid Res. 2005;44(1):68-97.

110. Kong G, Braun R, Dewhirst M. Characterization of the effect of hyperthermia on nanoparticle extravasation from tumor vasculature. Cancer Res. 2001;61(7):3027-32.

111. Kono K. Thermosensitive polymer-modified liposomes. Adv Drug Deliv Rev. 2001;53(3):307-19.

112. Kong G, Dewhirst M. Review hyperthermia and liposomes. Int $\mathbf{J}$ Hyperther. 1999;15(5):345-70.

113. Sofou S, Sgouros G. Antibody-targeted liposomes in cancer therapy and imaging. Expert Opin Drug Del. 2008;5(2):189-204.

114.• Dicheva BM, Koning GA. Targeted thermosensitive liposomes: an attractive novel approach for increased drug delivery to solid tumors. Expert Opin Drug Del. 2014;11(1):83-100. Deals with research updates on targeted thermosensitive-triggered drug delivery systems.

115. Puri A, Kramer-Marek G, Campbell-Massa R, Yavlovich A, Tele $\mathrm{SC}$, Lee SB, et al. HER2-specific affibody-conjugated thermosensitive liposomes (Affisomes) for improved delivery of anticancer agents. J Liposome Res. 2008;18(4):293-307.

116. Gaber MH. Modulation of doxorubicin resistance in multidrugresistance cells by targeted liposomes combined with hyperthermia. JBMBB. 2002;6(5):309-14.

117. Ren Y, Zhang H, Chen B, Cheng J, Cai X, Liu R, et al. Multifunctional magnetic $\mathrm{Fe}_{3} \mathrm{O}_{4}$ nanoparticles combined with chemotherapy and hyperthermia to overcome multidrug resistance. Int J Nanomedicine. 2012;7:2261-9.

118. Wang C, Wang X, Zhong T, Zhao Y, Zhang WQ, Ren W, et al. The antitumor activity of tumor-homing peptide-modified thermosensitive liposomes containing doxorubicin on MCF-7/ ADR: in vitro and in vivo. Int J Nanomedicine. 2015;10:2229-48.

119.• Torchilin V. Multifunctional and stimuli-sensitive pharmaceutical nanocarriers. Eur J Pharm Biopharm. 2009;71(3):431-44. Highlights recent advances with stimuli-sensitive nanoparticles and their therapeutic potentials.

120. Phillips WT, Goins BA, Bao A. Radioactive liposomes. Rev Nanomed Nanobiotechnol. 2009;1(1):69-83.

121. Kim DW, Andres ML, Li J, Kajioka EH, Miller GM, Seynhaeve ALB, et al. Liposome-encapsulated tumor necrosis factor- $\alpha$ enhances the effects of radiation against human colon tumor xenografts. J Interf Cytok Res. 2001;21(11):885-97.

122. Phillips W. Delivery of gamma-imaging agents by liposomes. Adv Drug Deliv Rev. 1999;37(1-3):13-32.

123. Torchilin VP. Multifunctional, stimuli-sensitive nanoparticulate systems for drug delivery. Nat Rev Drug Discov. 2014;13(11): 813-27.

124. Jones MN. Carbohydrate-mediated liposomal targeting and drug delivery. Adv Drug Deliv Rev. 1994;13(3):215-49.

125. van der Meel R, Vehmeijer LJC, Kok RJ, Storm G, van Gaal EVB. Ligand-targeted particulate nanomedicines undergoing clinical evaluation: current status. Adv Drug Deliv Rev. 2013;65(10): 1284-98.

126. Cheng Z, Al Zaki A, Hui J, Muzykantov V, Tsourkas A. Multifunctional nanoparticles: cost versus benefit of adding targeting and imaging capabilities. Science. 2012;338(6109): 903-10. 